\title{
COMPARATIVE STUDY OF THE WIND AND EARTHQUAKE DYNAMIC RESPONSES OF FIRE EXPOSED STEEL FRAMED BUILDINGS
}

\author{
Fabio Mazza ${ }^{1}$ and Marco Fiore ${ }^{2}$ \\ ${ }^{1}$ Dipartimento di Ingegneria Civile, Università della Calabria \\ Via P. Bucci, 87036 Rende (CS), Italy \\ fabio.mazza@unical.it \\ ${ }^{2}$ Dipartimento di Ingegneria Civile, Università della Calabria \\ Via P. Bucci, 87036 Rende (CS), Italy \\ fioremarco1989@libero.it
}

Keywords: Steel Framed Structures, Fire Scenarios, Time-Temperature Curves, Along-wind loads, Seismic Loads, Dynamic Analysis.

\begin{abstract}
Wind design of steel-framed buildings aims to provide appropriate stiffness and strength properties of the structural elements, so as to obtain an elastic behaviour, at the same time as controlling floor displacements and accelerations. On the other hand, in a seismic design it is commonly accepted that the structural members can undergo inelastic deformations under strong ground motions, provided that these deformations be kept within an acceptable threshold; moreover, deformability thresholds are also imposed at the serviceability limit state. Nevertheless, knowledge on the wind and seismic responses in the case of fire is lacking and an amplification of the structural response is expected in the case of existing structures exposed to fire. To evaluate the wind and seismic responses following a fire, a numerical investigation is carried out with reference to the steel framed structure of a ten-storey office building, which was designed for a low-risk zone under the former Italian seismic code and in line with Eurocodes 1 and 3. More specifically, the dynamic response of the test structure in a no fire situation, along the in-plan principal directions, is compared with what would happen in the event of fire, at $500^{\circ} \mathrm{C}, 550^{\circ} \mathrm{C}$ and $600^{\circ} \mathrm{C}$ fire temperatures, hypothesizing a reduction of stiffness and strength due to fire. Four fire scenarios have been considered on the assumption that the fire compartment is confined to the area of the first level (i.e. F1), the first two (i.e. F1/2) and the upper (i.e. Fi, $i=5,10)$ levels, with the parametric temperature-time fire curve evaluated in accordance with Eurocode 1. Dynamic analyses are carried out in the time domain using a step-by-step initial stress-like iterative procedure. Along-wind loads are considered assuming, at each level, time histories of the wind velocity for two return periods (i.e. $T_{r}=10$ or 50 years), based on an equivalent spectrum technique. Real accelerograms, whose response spectra match those adopted by Italian seismic code for a mediumrisk seismic zone and a medium subsoil class, are considered to simulate the seismic loads.
\end{abstract}




\section{INTRODUCTION}

The conventional design of steel framed buildings subjected to wind loads aims to provide stiffness and strength properties of the structural elements to control floor displacements and accelerations, such that an efficient use of the structure and suitable living comfort are guaranteed; in addition, there are provisions to avoid buckling and excessive deformability. On the other hand, in the aseismic design it is commonly accepted that the structural steel members can undergo inelastic deformations under strong ground motions, provided that be kept within an acceptable threshold, while damage limitation requirements are also imposed at the serviceability limit state. However, stiffness and strength properties of steel degrade at high temperatures and this deterioration needs to be properly accounted for in the design of steel structures in the event of fire [1]. The occurrence of fire following earthquake has gained attention of many recent numerical and experimental studies into the nonlinear response of steel [2-5] and composite steel-concrete [6] structures. Nevertheless, knowledge on the wind and seismic dynamic responses of steel framed buildings damaged by fire is lacking and an amplification of the structural response for the serviceability and ultimate limit states is to be expected in such cases. Moreover, little attention has been paid to the influence of fire scenarios on the structural behaviour of steel framed buildings.

In the present work, the wind and earthquake responses of steel framed structures in a no fire situation, along the in-plan principal directions, are compared with those in which fire occurs, at $500^{\circ} \mathrm{C}, 550^{\circ} \mathrm{C}$ and $600^{\circ} \mathrm{C}$ temperatures, assuming stiffness and strength properties of the frame members in line with the reduction factors proposed by Eurocode 3 [7]. To this end, ten-storey steel office buildings are designed in line with the previous Italian seismic code [8] for a low-risk zone, as well as the provisions of Eurocode 3. Wind actions are evaluated in compliance with Eurocode 1 [9]. Four fire scenarios are hypothesized assuming the fire compartment confined to the area of the first level (i.e. F1), the first two (i.e. F1/2) and the upper (i.e. $\mathrm{Fi}, \mathrm{i}=5,10)$ levels, with the parametric temperature-time fire curve evaluated in line with Eurocode 1. In order to consider along-wind loads, at each storey, time histories of the wind velocity for two return periods (i.e. $T_{r}=10$ or 50 years) are assumed, in accordance with an equivalent spectrum technique [10]. Then, real accelerograms, whose response spectra match those adopted by the current Italian seismic code [11] for a medium-risk seismic zone and a medium subsoil class, are considered to simulate seismic loads. Finally, dynamic analyses are carried out in the time domain through a step-by-step initial stress-like iterative procedure [12, 13]. For this purpose, the frame members are idealized by a bilinear model, which allows the simulation of the nonlinear behaviour under seismic loads $[14,15]$.

\section{STEEL TEST STRUCTURE: DESIGN AND FIRE MODELLING}

The symmetric steel structure, with a rectangular plan (Figure 1a), of a ten-storey office building (Figure 1c) is considered as test structure in this study. More precisely, moment resisting frames are placed to carry (horizontal) wind or seismic loads, while a grid of main and secondary girders support at the floor levels a composite deck with horizontal bracing. A simulated design of the test structure is carried out in line with the previous Italian seismic code (DM96, [8]), for a low-risk seismic region (degree of seismicity $S=6$, which corresponds to a coefficient of seismic intensity $C=0.04$ ), a medium subsoil class (subsoil parameter $\varepsilon=1$ ) and a coefficient of seismic protection equal to 1.2. Wind actions are evaluated in compliance with Eurocode 1 [9], assuming: flat terrain with a roughness length of $0.30 \mathrm{~m}$; urban area (class B of terrain roughness) with a reference velocity of $28 \mathrm{~m} / \mathrm{s}$, which represents a mean value of those assumed for the nine zones of the Italian wind map; altitude of $500 \mathrm{~m}$ above sea level. Moreover, the test structure also satisfies the ultimate limit states for strength and 
buckling evaluated in accordance with Eurocode 3 [7]. An ultimate strength of $510 \mathrm{~N} / \mathrm{mm}^{2}$ is assumed for the steel frame members, for which ductile cross-sections regularly tapering in elevation are selected in accordance with class 1 of Eurocode 3 (Figure 1c). For the sake of simplicity, the plane frames orientated along the horizontal earthquake and wind directions (i.e. $\mathrm{X}$ and $\mathrm{Y}$ shown in Figure 1a) are considered as a reference scheme.

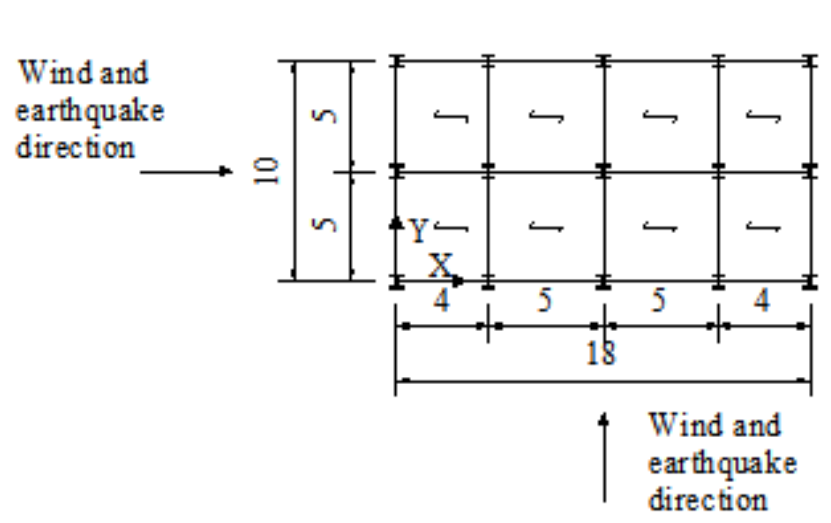

(a) Plan.

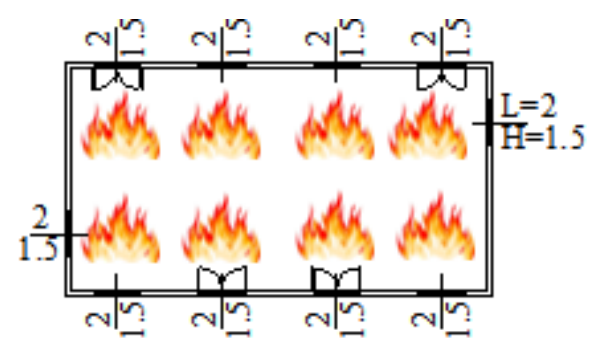

(b) Fire compartment.

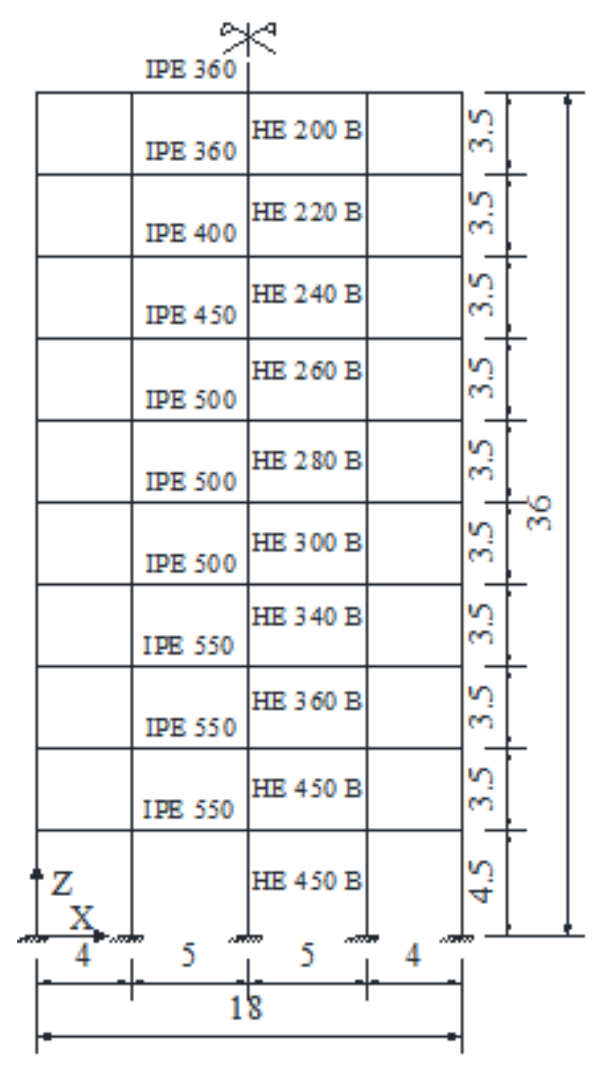

(c) Elevation.

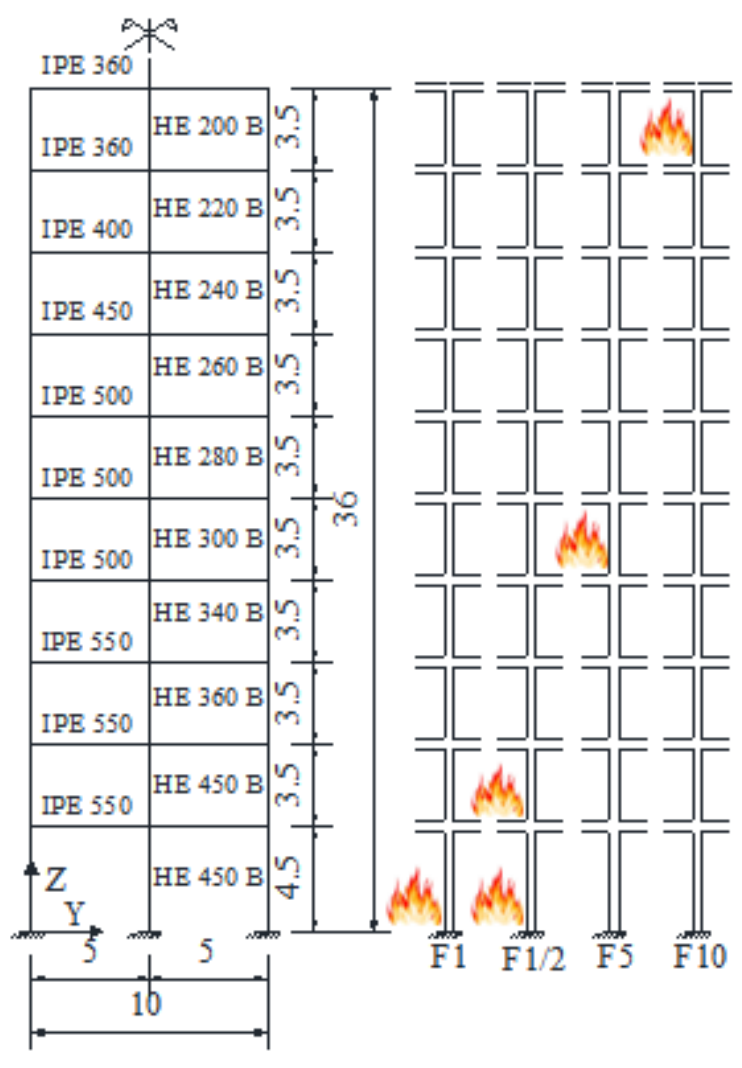

(d) Fire scenarios.

Figure 1: Steel test structure (dimensions in $\mathrm{m}$ ).

The gravity loads considered in the design are represented by dead loads of 3.66 and 4.51 $\mathrm{kN} / \mathrm{m}^{2}$ for the top floor and the others, respectively, and a live load of $3 \mathrm{kN} / \mathrm{m}^{2}$ for all floors. The weight of sandwich panels, regularly distributed in elevation as external cladding of the building, is taken into account with a dead load of $1.4 \mathrm{kN} / \mathrm{m}$. The dynamic properties of the six main vibration modes are reported in Table 1: i.e. vibration period $\left(T_{i}\right)$; effective masses in the $\mathrm{X}\left(m_{E, X}\right)$ and $\mathrm{Y}\left(m_{E, Y}\right)$ directions, expressed as percentage of the total mass $\left(m_{t o t}\right)$. 


\begin{tabular}{llll}
\hline Vibration Mode & $T_{i}[\mathrm{~s}]$ & $m_{E, X}\left[\% m_{\text {tot }}\right]$ & $m_{E, Y}\left[\% m_{\text {tot }}\right]$ \\
\hline 1 & 1.938 & 80.5 & 0 \\
2 & 1.402 & 0 & 72.3 \\
3 & 0.787 & 13.1 & 0 \\
4 & 0.549 & 0 & 15.2 \\
5 & 0.475 & 3.6 & 0 \\
6 & 0.330 & 0 & 5.8 \\
\hline
\end{tabular}

Table 1: Dynamic properties of the test structure $\left(m_{t o t}=10.6 \mathrm{kNs}^{2} / \mathrm{cm}\right)$.

Four fire scenarios have been reported in Figures $1 \mathrm{~b}$ and $1 \mathrm{~d}$, assuming the fire compartment confined to the area of the first level (i.e. F1), the first two (i.e. F1/2) and the upper (i.e. $\mathrm{Fi}, \mathrm{i}=5,10)$ levels. It is worth noting that $\mathrm{F} 1 / 2$ fire scenario is obtained from the F1 and F2 ones, which are assumed to occur simultaneously. The geometric properties of the fire compartment are reported in Table 2, assuming three values of the maximum temperature (i.e. $T=500^{\circ} \mathrm{C}, 550^{\circ} \mathrm{C}$ and $600^{\circ} \mathrm{C}$ ) for the first and the upper levels: i.e. $L, D$ and $H$ representing length, depth and height, respectively; $A f$, floor area; $A t$, total area of enclosure (i.e. walls, ceiling and floor, including openings); $A_{v}$, total area of vertical openings; $h_{e q}$, weighted average height of windows. From these values it is possible to define an opening factor, representing the amount of ventilation:

$$
O=A_{v} h_{e q}^{0.5} / A_{t}
$$

\begin{tabular}{|c|c|c|c|c|c|c|c|c|c|}
\hline Fire compartment & $L[\mathrm{~m}]$ & $D[\mathrm{~m}]$ & $H[\mathrm{~m}]$ & $A_{f}\left[\mathrm{~m}^{2}\right]$ & $A_{t}\left[\mathrm{~m}^{2}\right]$ & $h_{e q}[\mathrm{~m}]$ & $T\left[{ }^{\circ} \mathrm{C}\right]$ & $A_{v}\left[\mathrm{~m}^{2}\right]$ & $O\left[\mathrm{~m}^{0.5}\right]$ \\
\hline \multirow{3}{*}{ First level } & \multirow{3}{*}{18} & \multirow{3}{*}{10} & \multirow{3}{*}{4.5} & \multirow{3}{*}{180} & \multirow{3}{*}{612} & \multirow{3}{*}{1.5} & 500 & 9 & 0.018 \\
\hline & & & & & & & 550 & 12 & 0.024 \\
\hline & & & & & & & 600 & 15 & 0.030 \\
\hline \multirow{3}{*}{ Upper levels } & \multirow{3}{*}{18} & \multirow{3}{*}{10} & \multirow{3}{*}{3.5} & \multirow{3}{*}{180} & \multirow{3}{*}{556} & \multirow{3}{*}{1.5} & 500 & 9 & 0.020 \\
\hline & & & & & & & 550 & 12 & 0.026 \\
\hline & & & & & & & 600 & 12 & 0.026 \\
\hline
\end{tabular}

Table 2: Geometric properties of fire compartment.

As an example, the distribution of windows opened at the upper levels, corresponding to $A_{v}=12 \mathrm{~m}^{2}$, is shown in Figure 1b. It is worth noting that the uniform temperature in the selected compartment is considered to be the most severe condition for the fire before wind or earthquake. Several models can be used to simulate the time-temperature evolution during an actual fire, from the flashover to the full development: conventional fire curves (e.g. the standard ISO-834 curve [16]), in which temperature monotonically increasing with time represents the heating phase only when the fuel supply is assumed to be inexhaustible; natural fire curves (e.g. the EC1 curve [9]), in which temperature depends on the ventilation and fire load in the compartment and the cooling phase is represented, based on the assumption that, at a certain point, either the air or the combustible material will diminuish.

The EC1 parametric fire curve is used in the present study, on the assumption that the fire load of the compartment is completely burnt out. In the heating phase, the gas temperature (in $\left.{ }^{\circ} \mathrm{C}\right)$

$$
\theta_{g}=20+1325\left(1-0.324 e^{-0.2 t^{*}}-0.204 e^{-1.7 t^{*}}-0.472 e^{-19 t^{*}}\right)
$$

is a function of a fictitious time $t^{*}$ obtained considering the time $t$ (in hours) multiplied by a dimensionless parameter equal to

$$
\Gamma=(O / b)^{2} /(0.04 / 1160)^{2}
$$


where $b$ is the thermal absorptivity of surrounding surfaces of the compartment

$$
b=\sqrt{\rho c \lambda}
$$

$\rho$ being the density, $c$ the specific heat and $\lambda$ the thermal conductivity of boundary of enclosure.

The gas temperature in the cooling phase is given by

$$
\begin{aligned}
& t_{\max }^{*} \leq 0.5 h \rightarrow \theta_{g}=\theta_{\max }-625\left(t^{*}-t_{\max }^{*}\right) \\
& 0.5 h<t_{\max }^{*}<2 h \rightarrow \theta_{g}=\theta_{\text {max }}-250\left(3-t_{\max }^{*}\right)\left(t^{*}-t_{\max }^{*}\right) \\
& t_{\max }^{*} \geq 2 h \rightarrow \theta_{g}=\theta_{\text {max }}-250\left(t^{*}-t_{\max }^{*}\right)
\end{aligned}
$$

where the maximum temperature $\theta_{\max }$ in the heating phase happens for

$$
t_{\max }^{*}=\left(0.2 \cdot 10^{-3} q_{t, d} / O\right) \Gamma
$$

being the design fire load density

$$
q_{t, d}=q_{f, d} A_{f} / A_{t}
$$

related to the value $q_{f, d}$ corresponding to the surface area of the floor $\left(A_{f}\right)$. Further details on fire modelling can be found in $[17,18]$.

Finally, the standard ISO-834 curve is defined as [16]

$$
\theta_{g}=20+345 \log _{10}(8 t+1)
$$

where $t$ is expressed in hours.

With reference to the fire scenarios shown in Figure 1, the ISO and EC1 time-temperature curves are compared in Figure 2 in the case where a fire compartment is confined to the area of the first level (Figure 2a) and the upper ones (Figure 2b). Fire parameters, for the openedplan office building, are reported in Table 3 assuming three values of the maximum temperature (i.e. $T=500^{\circ} \mathrm{C}, 550^{\circ} \mathrm{C}$ and $600^{\circ} \mathrm{C}$ ) in the $\mathrm{EC} 1$ time-temperature curves.

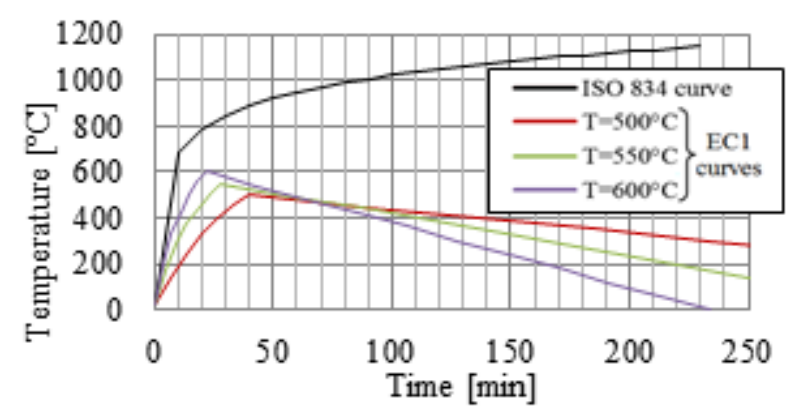

(a) Fire compartment at $1^{\text {st }}$ level.

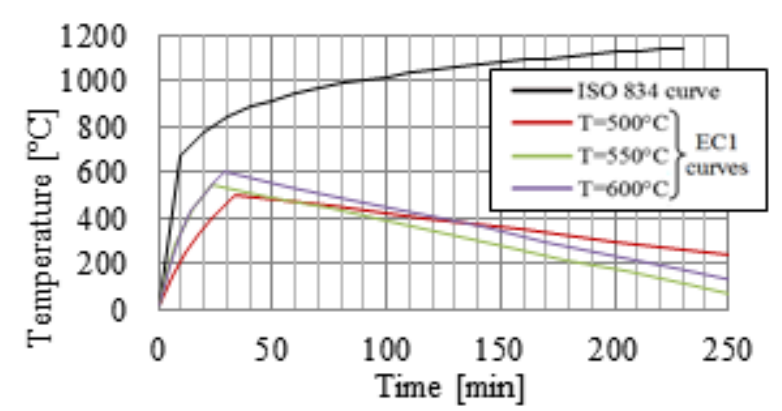

(b) Fire compartment at upper levels.

Figure 2: Conventional (ISO 834) and natural (EC1) fire curves.

\begin{tabular}{l|lll|lll}
\hline & \multicolumn{3}{|c|}{ First level } & \multicolumn{3}{c}{ Upper levels } \\
\hline$T\left({ }^{\circ} \mathrm{C}\right)$ & $q_{f, d}\left(\mathrm{MJ} / \mathrm{m}^{2}\right)$ & $b\left(\mathrm{~J} / \mathrm{m}^{2} \mathrm{~s}^{1 / 2} \mathrm{~K}\right)$ & $t_{\text {max }}^{*}(\mathrm{~h})$ & $q_{f, d}\left(\mathrm{MJ} / \mathrm{m}^{2}\right)$ & $b\left(\mathrm{~J} / \mathrm{m}^{2} \mathrm{~s}^{1 / 2} \mathrm{~K}\right)$ & $t_{\text {max }}^{*}(\mathrm{~h})$ \\
\hline 500 & 203.44 & 1660 & 0.07 & 174.43 & 1692 & 0.07 \\
550 & 186.91 & 1666 & 0.08 & 160.47 & 1699 & 0.08 \\
600 & 186.21 & 1671 & 0.10 & 198.11 & 1696 & 0.10 \\
\hline
\end{tabular}

Table 3: Fire parameters in the EC1 time-temperature curves [9]. 


\section{NUMERICAL RESULTS: FIRE BEFORE WIND AND EARTHQUAKE}

Once the time-temperature curve of the fire compartment is determined with the EC1 model, it becomes possible to evaluate the reduction factors $(K)$ of effective yield strength $\left(f_{y, \theta}\right)$, proportional limit $\left(f_{p, \theta}\right)$ and slope of the linear elastic range $\left(E_{s, \theta}\right)$ of stress-strain law of the steel at the maximum temperature $(T)$ of $500{ }^{\circ} \mathrm{C}, 550^{\circ} \mathrm{C}$ and $600^{\circ} \mathrm{C}$ (Figure 3). As can be observed, a decrease of stiffness (i.e. $K_{E, \theta}$ ) and yield strength (i.e. $K_{y, \theta}$ ) from a minimum, of about $40 \%$ and $22 \%$ at $T=500^{\circ} \mathrm{C}$, and a maximum, of about $69 \%$ and $53 \%$ at $T=600^{\circ} \mathrm{C}$, respectively, is obtained in line with Eurocode 3 [7].
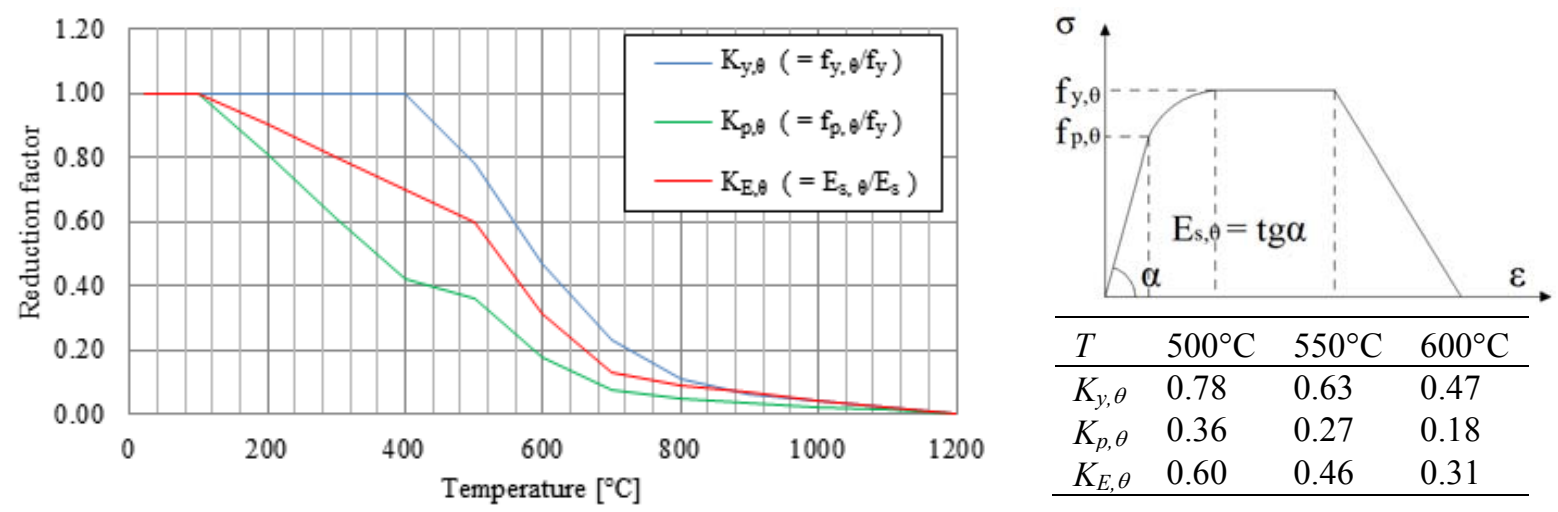

Figure 3: Reduction factors for the steel stress-strain law at high temperatures [7].

Subsequently, the residual seismic load capacity of the cross-sections after fire, in terms of stiffness and strength reductions, is evaluated. In detail, columns and girders are considered exposed to fire on all sides in accordance with the assumption of uniform temperature distribution in cross-section. This hypothesis is justified by the high thermal conductivity of steel and the thinness of the cross-sections. In Figure 4, flexural stiffness of steel columns is reported along the building height, assuming a direct correspondence between the examined level and the fire compartment. In particular, major (i.e. $E I_{y}$ in Figure $4 \mathrm{a}$ ) and minor (i.e. $E I_{z}$ in Figure $4 \mathrm{~b}$ ) axes of bending are examined at the maximum temperatures $T=500^{\circ} \mathrm{C}, T=550^{\circ} \mathrm{C}$ and $T=600^{\circ} \mathrm{C}$. Note that a local decrease in stiffness from a minimum of about $40 \%$ to a maximum of about $69 \%$ is obtained in comparison with the no-fire condition. Similar results are reported in Figure 5a with reference to the longitudinal and transversal girders.

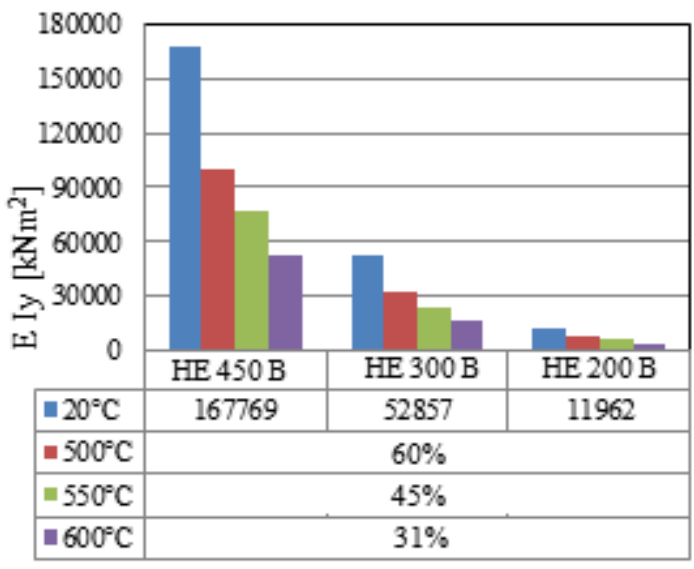

(a) Major bending axis.

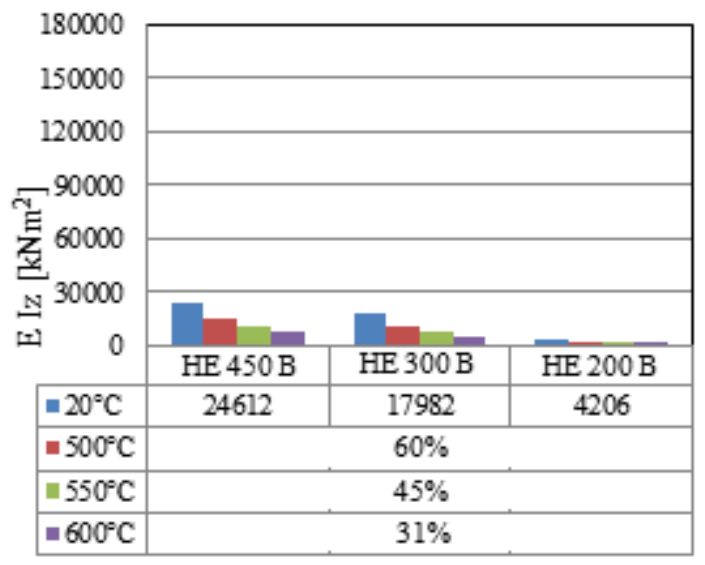

(b) Minor bending axis.

Figure 4: Flexural stiffness of steel columns exposed to fire. 


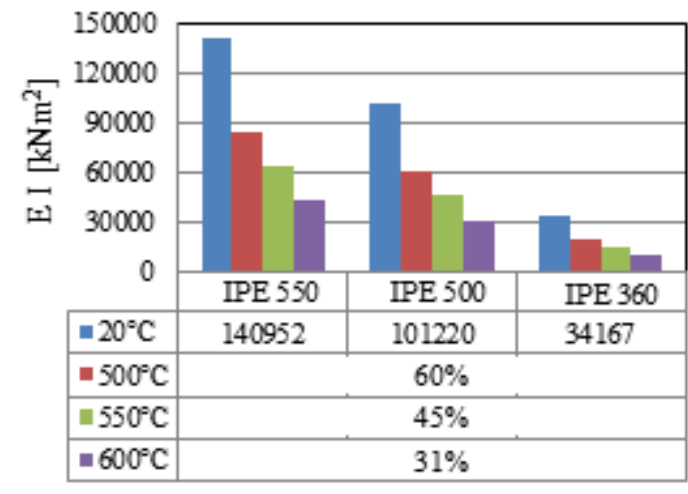

(a) Flexural stiffness.

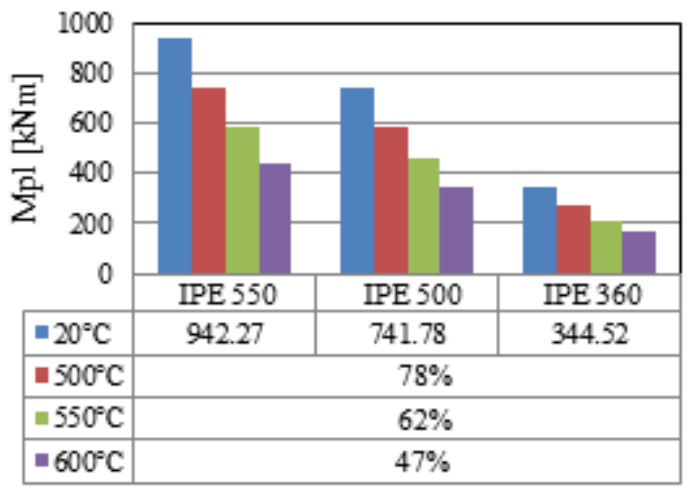

(b) Plastic moment.

Figure 5: Mechanical properties of steel girders exposed to fire.

Finally, results are reported for the plastic bending moment $(M)$ of girders (Figure $5 \mathrm{~b}$ ) and plastic interaction domain between axial load $(N)$ and bending moment $(M)$ of columns (Figure 6). A simplified calculation is carried out based on an elastic-perfectly plastic stress-strain law of the steel with reduced values of elasticity modulus and yield strength. Moreover, the $\mathrm{N}$ $M$ domain is obtained analogously to the provisions of EC3, simply by replacing the plastic axial load under uniform compression with the buckling load.

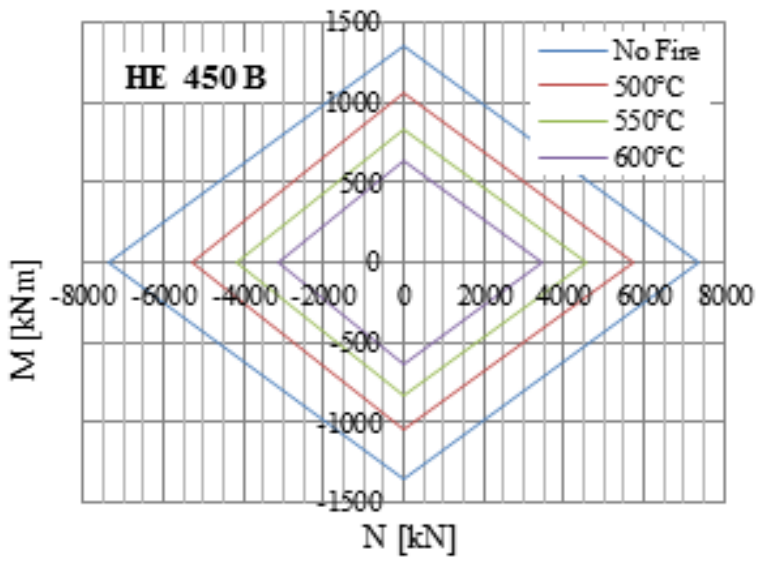

(a) Major bending axis $\left(1^{\text {st }}\right.$ storey/F1).

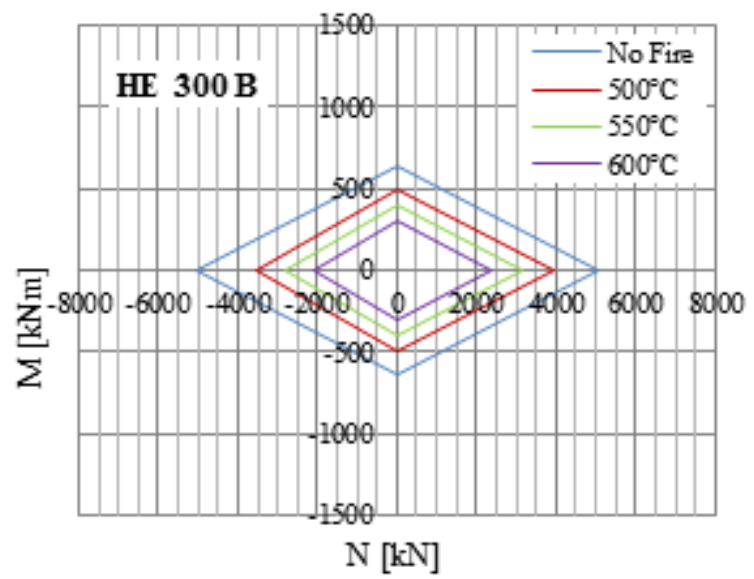

(c) Major bending axis ( $5^{\text {th }}$ storey/F5).

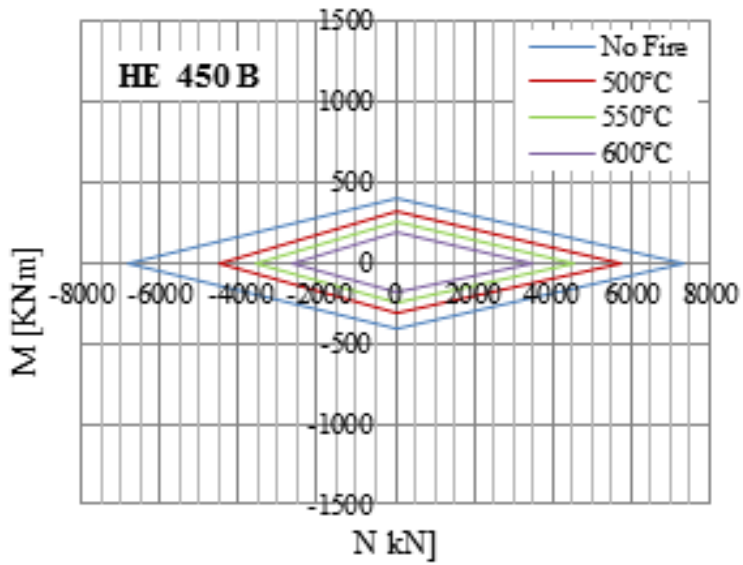

(b) Minor bending axis $\left(1^{\text {st }}\right.$ storey/F1).

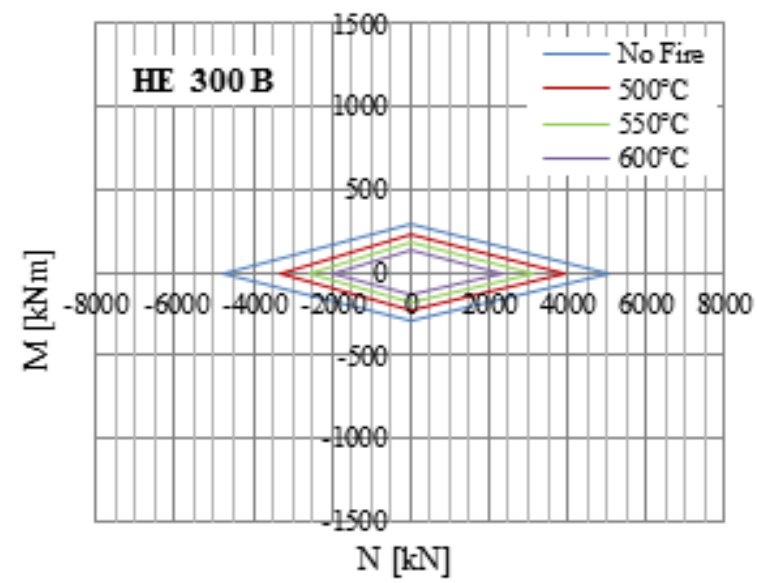

(d) Minor bending axis ( $5^{\text {th }}$ storey/F5).

Figure 6: Plastic $N-M$ domains of steel columns exposed to fire. 
Only the fire compartments at the first (i.e. F1 scenario in Figures $6 a$ and $6 \mathrm{~b}$ ) and fifth (i.e. F5 scenario in Figures 6c and 6d) levels are examined for the columns. As can be observed, a significant decrease in strength is observed for the girders, with a maximum local reduction of about $53 \%$ in the case of $T=600^{\circ} \mathrm{C}$ (Figure $5 \mathrm{~b}$ ). On the other hand, the columns exhibit a marked narrowing of their $N-M$ domains, especially for the buckling load showing a maximum reduction of $29 \%$ and $34 \%$, at the first storey, and $57 \%$ and $61 \%$, at the fifth storey, along major (Figures 6a and 6c) and minor (Figures 6b and 6d) axes of bending, respectively.

\section{NUMERICAL RESULTS: WIND LOADING FOLLOWING FIRE}

In order to study the dynamic behaviour of the steel structures damaged by the fire loading proposed in Section 3, whose properties are illustrated in Section 2, a computer code for timedomain analysis of frames subjected to wind pressure is adopted [12, 13]. For the sake of simplicity, only the along-wind component of the velocity is taken into account in the in-plan $\mathrm{X}$ and $\mathrm{Y}$ principal directions (Figure 1a). The instantaneous wind velocity at each floor level of the building is given by the superimposition of a mean wind velocity, with a logarithmic profile along the height depending on the surface roughness, and a zero mean velocity fluctuation, corresponding to a stochastic stationary Gaussian process. More precisely, wind loads are schematized by means of the equivalent wind spectrum technique [10]. The equivalence criterion is formulated by defining a fictitious velocity fluctuation, which is a random function of time but invariant and perfectly cross-correlated in space. A Monte Carlo simulation is adopted to generate time histories of the wind velocity at each floor level: a duration of $600 \mathrm{~s}$ and a step $\Delta t=0.2 \mathrm{~s}$ are assumed for two return periods (i.e. $T_{r}=10$ or 50 years).

At first, maximum values of floor displacement $\left(u_{\max }\right)$ and storey drift $\left(\Delta_{\max } / h\right)$ are plotted along the frame height in Figures 9 and 10, respectively, comparing steel structures in no-fire condition and fire exposed at a maximum temperature of $500{ }^{\circ} \mathrm{C}$ (i.e. T500 in Figures $9 \mathrm{a}$ and 10a) and $600{ }^{\circ} \mathrm{C}$ (i.e. T600 in Figures $9 \mathrm{~b}$ and 10b). At the same time, three fire scenarios are examined on the assumption that the fire compartment is confined to the area of the first (i.e. F1), fifth (i.e. F5) and tenth (i.e. F10) levels. A black line reports the deformability limits imposed by EC3 [7] on the top displacement (i.e. 1/500 of the building height) and storey drift (i.e. $1 / 300$ of the storey height).

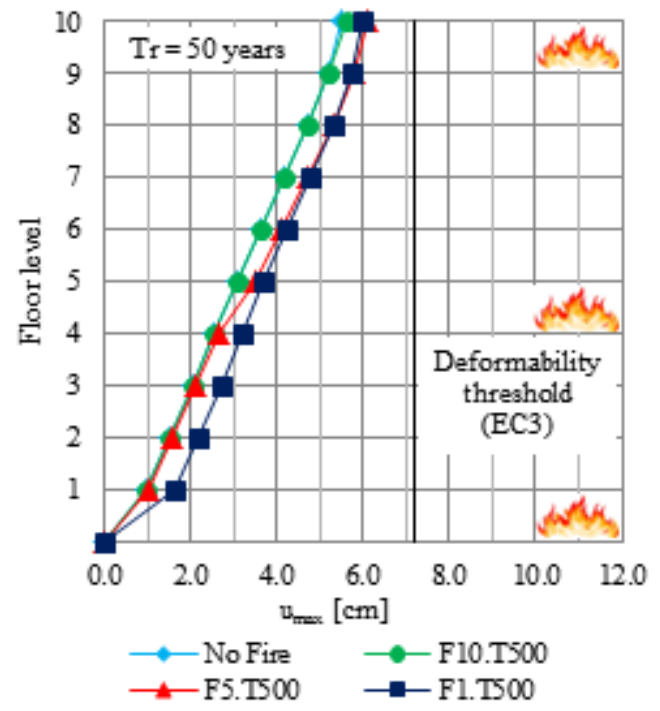

(a) $T=500^{\circ} \mathrm{C}$.

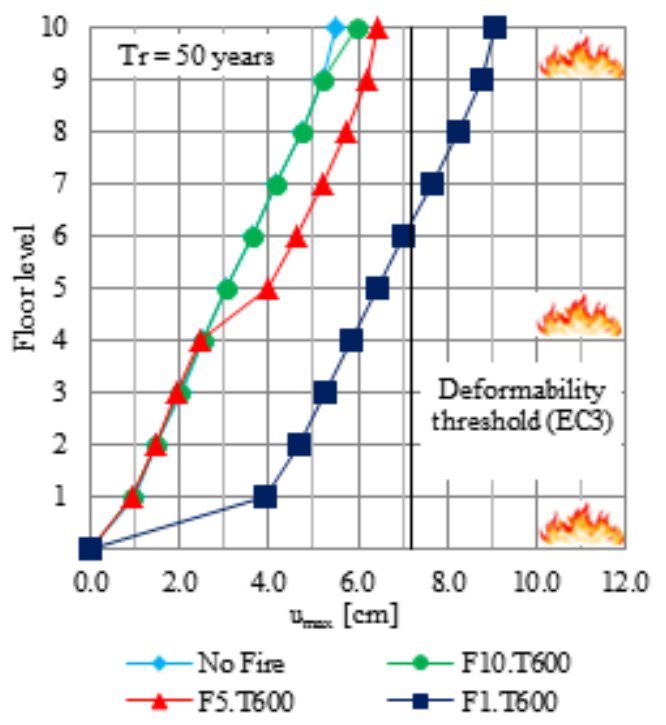

(b) $T=600^{\circ} \mathrm{C}$.

Figure 9: Maximum floor displacement for three fire scenarios: wind loads along $\mathrm{X}$ direction. 


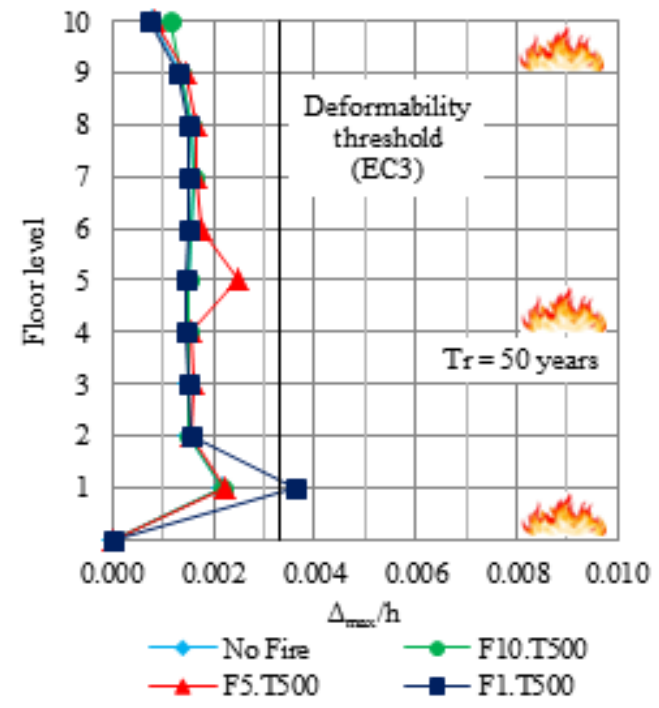

(a) $T=500^{\circ} \mathrm{C}$.

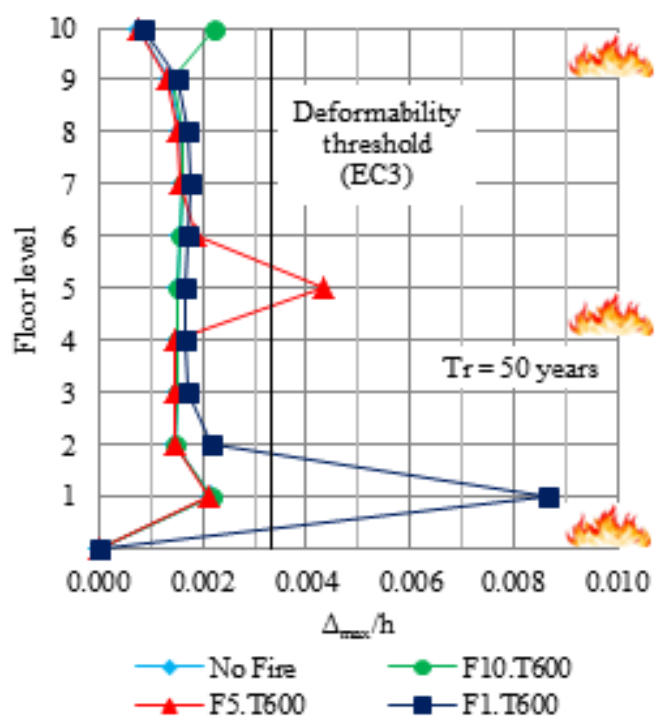

(b) $T=600^{\circ} \mathrm{C}$.

Figure 10: Maximum storey drift for three fire scenarios: wind loads along $\mathrm{X}$ direction.

For the sake of brevity, only results in the flexible direction of the building plan (i.e. the X direction) are reported. As can be observed in Figure 9b, the maximum top lateral displacement of the F1.T600 structure has exceeded the corresponding deformability threshold imposed by EC3. This behaviour is due to a soft-storey mechanism at the first level when the fire scenario F1 is assumed, with a lateral displacement curve similar to that of the structure in the no-fire condition at the upper floors. Moreover, the maximum storey drift of the F1.T500 structure (Figure 10a) and F1.T600 and F5.T600 structures (Figure 10b) exceeds the deformability threshold imposed by EC3 only at the levels where the fire compartment occurs.

Thereafter, analogous curves to those reported above are shown in Figures 11 (i.e. $\left.u_{\max }\right)$ and 12 (i.e. $\Delta_{\max } / \mathrm{h}$ ), where fire compartment is confined to the area of the first two levels (i.e. $\mathrm{F} 1 / 2$ ), comparing the no-fire condition with results for three values of the maximum fire temperature (i.e. $T=500^{\circ} \mathrm{C}, 550^{\circ} \mathrm{C}$ and $600^{\circ} \mathrm{C}$ ).

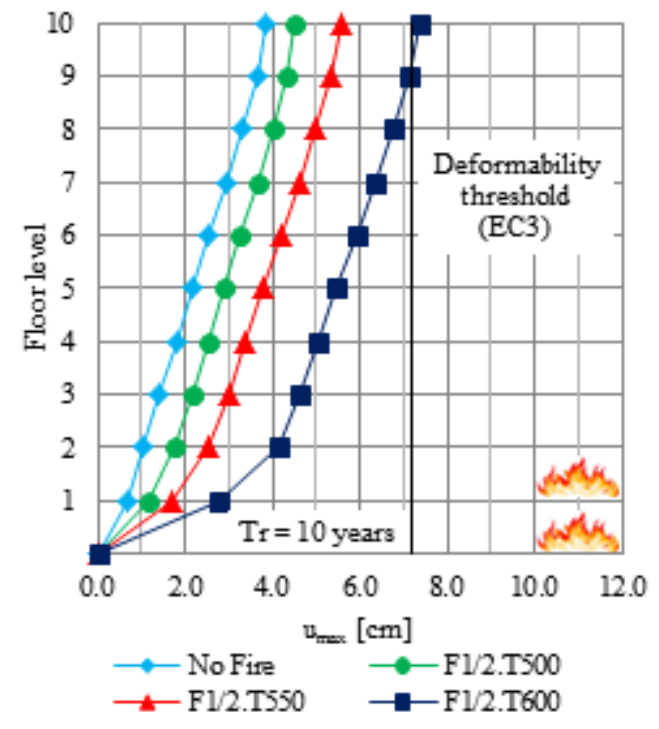

(a) $T_{r}=10$ years.

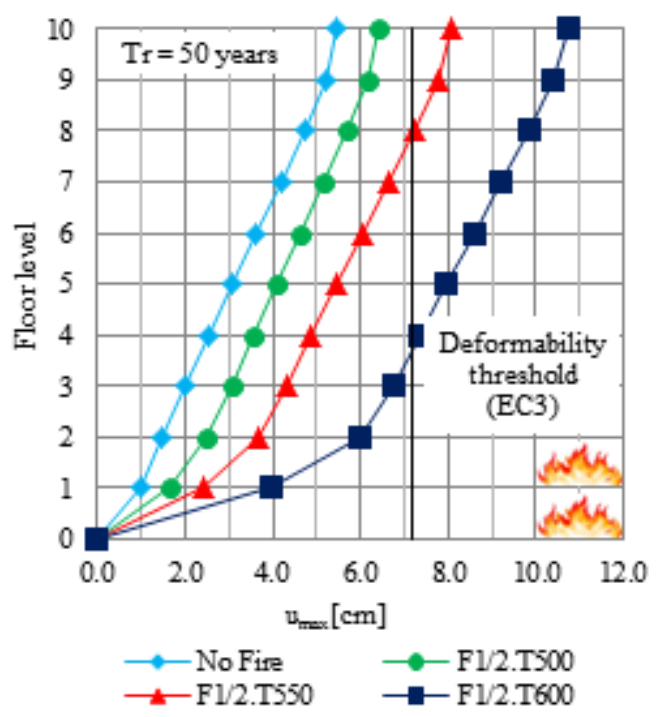

(b) $T_{r}=50$ years.

Figure 11: Maximum floor displacement for three fire temperatures: wind loads along X direction. 


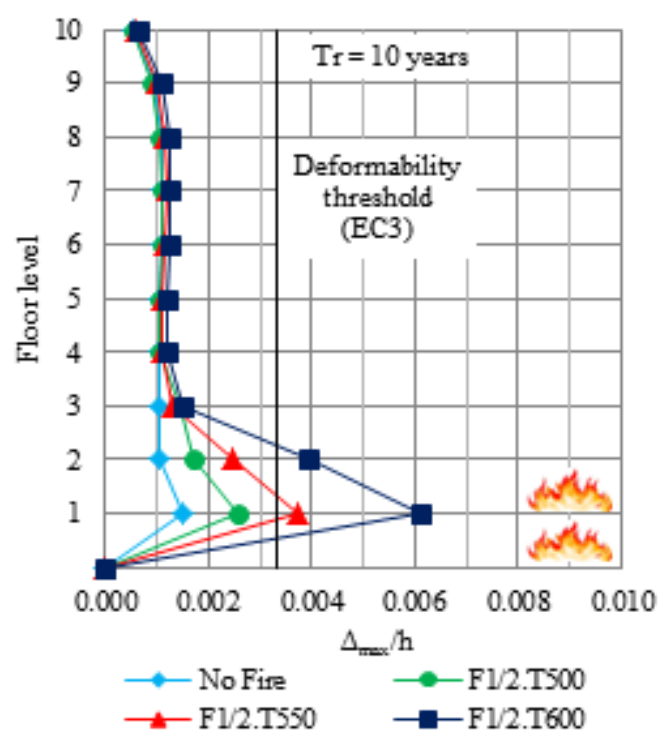

(a) $T_{r}=10$ years.

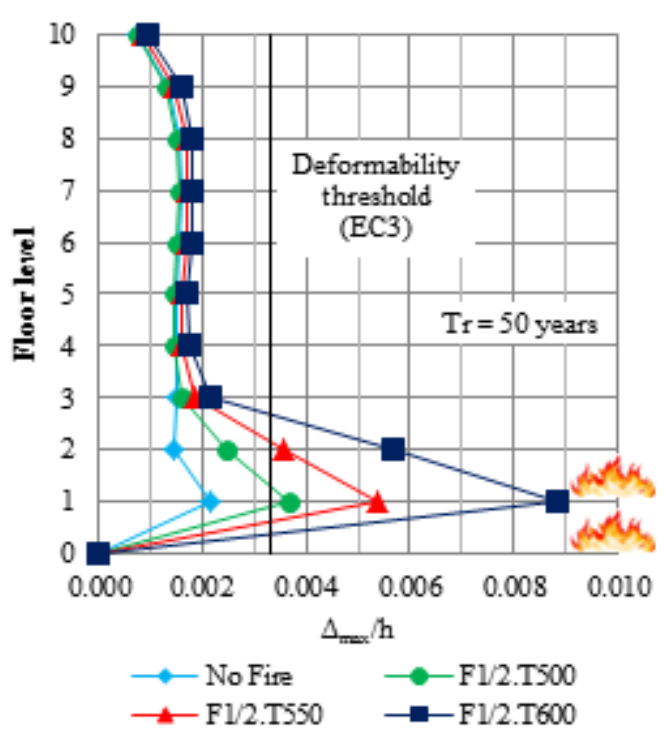

(b) $T_{r}=50$ years.

Figure 12: Maximum storey drift for three fire temperatures: wind loads along $\mathrm{X}$ direction.

More specifically, effects of wind loads with return period of $T_{r}=10$ years (Figures $11 \mathrm{a}$ and 12a) and $T_{r}=50$ years (Figures $11 \mathrm{~b}$ and $12 \mathrm{~b}$ ) are compared along the X direction. As can be observed, when $T_{r}=50$ years is assumed, it is not possible to obtain values of the top floor maximum displacement below the EC3 threshold for the F1/2.T550 and F1/2.T600 structures (Figure 11b). On the other hand, the maximum storey drift exceeds the EC3 threshold at the first level of the F1/2.T550 and F1/2.T600 structure, even if $T_{r}=10$ years is assumed (Figure $12 \mathrm{a}$ ), and also at the second level, when $T_{r}=50$ years is considered (Figure $12 \mathrm{~b}$ ).

Finally, maximum floor acceleration (i.e. $\mathrm{amax}$ ) along the frame height is plotted in the stiff direction of the building plan (i.e. the $\mathrm{Y}$ direction), for both $T_{r}=10$ years (Figures 14a) and $T_{r}=50$ years (Figures 13a,b and 14b), comparing three fire scenarios (i.e. F1, F5 and F10 for fire temperatures of $500^{\circ} \mathrm{C}$ and $600^{\circ} \mathrm{C}$ : Figure 13) and three fire temperatures (i.e. $T=500^{\circ} \mathrm{C}$, $550^{\circ} \mathrm{C}$ and $600^{\circ} \mathrm{C}$ for fire scenario F1/2: Figure 14).

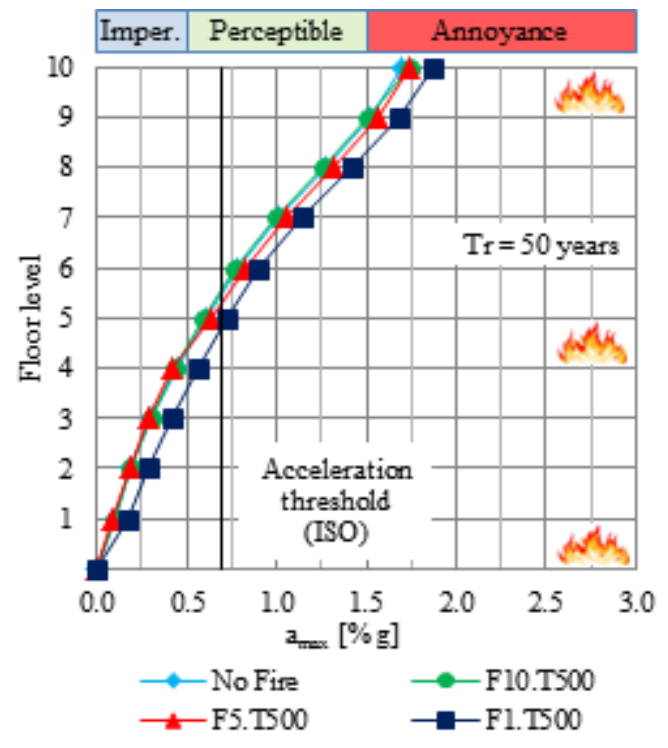

(a) $T=500^{\circ} \mathrm{C}$.

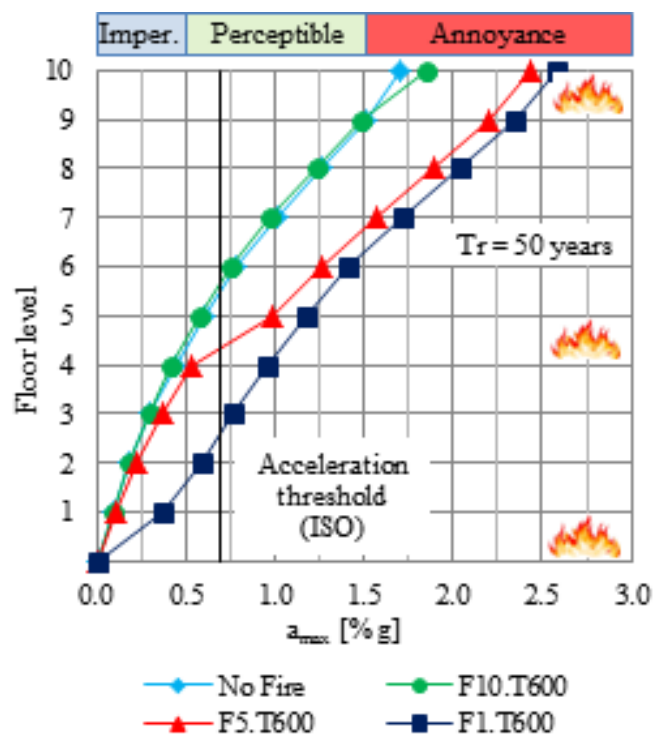

(b) $T=600^{\circ} \mathrm{C}$.

Figure 13: Maximum floor acceleration for three fire scenarios: wind loads along Y direction. 


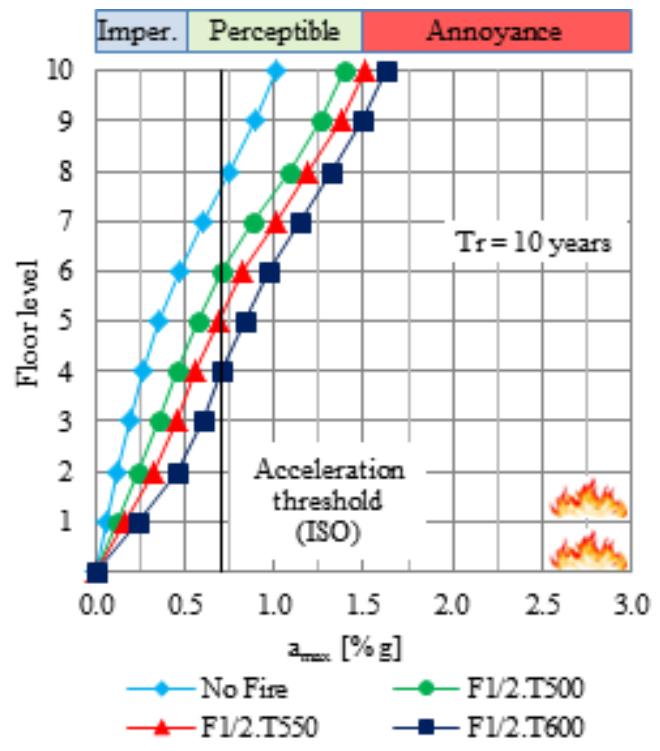

(a) $T_{r}=10$ years.

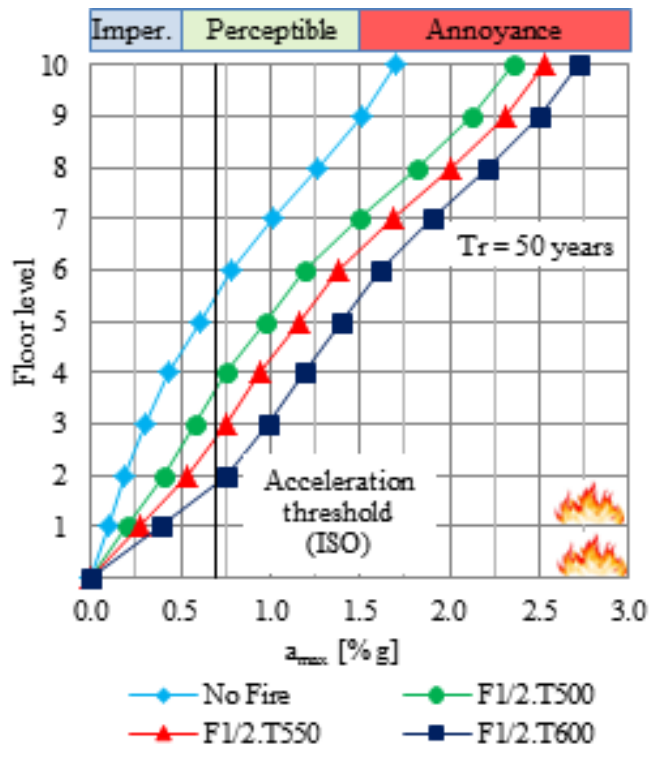

(b) $T_{r}=50$ years.

Figure 14: Maximum floor acceleration for three fire temperatures: wind loads along Y direction.

As a reference, the perception thresholds associated with various degrees of human discomfort are formulated in terms of critical values of the wind-induced building acceleration, expressed as percentage of the gravity acceleration g (e.g. [19], the maximum acceleration, $\mathrm{a}_{\max }$, can be assumed as: imperceptible, for $\mathrm{a}_{\max }<0.5 \% \mathrm{~g}$; perceptible, for $\mathrm{a}_{\max }=0.5 \% \mathrm{~g} \div 1.5 \% \mathrm{~g}$; annoyance, for $\mathrm{a}_{\max }=1.5 \% \mathrm{~g} \div 5 \% \mathrm{~g}$ ). The ISO code threshold is also shown [20], which assigns a value of $0.7 \% \mathrm{~g}$ to the standard deviation at the top floor of office buildings. For all fire scenarios, note that the number of levels where the ISO discomfort threshold is exceeded increases for increasing values of fire temperature (Figures 13 and 14) and return period of the wind loads (Figure 14). Moreover, it is not possible to obtain values of amax lower than the annoyance range in the event of fire at the first two levels and $T_{r}=50$ years (Figure 14b).

\section{NUMERICAL RESULTS: EARTHQUAKE LOADING FOLLOWING FIRE}

In order to study the seismic response of the steel framed building along the in-plan $X$ and Y principal directions, nonlinear dynamic analyses are carried out through a step-by-step procedure based on a two parameter implicit integration scheme [21-24]. At each step of the analysis, the final state, satisfying the equilibrium equations within an assigned tolerance, is determined using an initial stress-like iterative procedure $[14,15]$. To account for the inelastic deformation due to the seismic loads, the frame members are idealized by a lumped plasticity model constituted of two components, one elastic-perfectly plastic and the other simply elastic, assuming a hardening ratio of $2 \%$. Moreover, the influence of both axial load and slenderness on the yield moment of the columns is considered over time. The axial-force bending moment interaction domain is obtained analogously to the provisions of EC3 [7], simply by replacing the plastic axial load under uniform compression with the buckling load.

Seven recorded accelerograms, corresponding to a medium-risk seismic region provided by the current Italian seismic code (NTC08, [11]) and a design subsoil class $B$ (i.e. subsoil stratigraphic parameter $S_{S}=1.2$ ), are selected by the computer code REXEL [25]. The corresponding elastic response spectra of normalized acceleration match, on average, NTC08 spectrum for the serviceability (i.e. damage) limit state, based on an equivalent viscous damping ratio in the horizontal direction equal to $2 \%$. All the following results are obtained as an average of those separately obtained for the real motions. 
Maximum storey drift along the in-plan X (Figure 15a) and Y (Figure 15b) directions are plotted for the fire temperature $T=600^{\circ} \mathrm{C}$, comparing framed structures both in the no-fire condition and on the assumption that fire scenarios on the first (i.e. F1), fifth (i.e. F5) and tenth (i.e. F10) levels are considered. Moreover, curves analogous are also shown in Figure 16 , where the fire compartment is confined to the area of the first two levels (i.e. F1/2 scenario) at three fire temperatures (i.e. $T=500^{\circ} \mathrm{C}, 550^{\circ} \mathrm{C}$ and $600^{\circ} \mathrm{C}$ ). A black line plots the damage limitation requirement imposed by NTC08 (i.e. 1/200 of the storey height). As can be observed, an amplification in the structural response of fire-exposed structures is localized to the level of the fire compartment involved, where the damage threshold is exceeded, while it declines, in comparison with the no-fire condition, on the other levels where fire is not considered. This behaviour is amplified when the F1.T600 (Figure 15a) and F1/2.T600 (Figure 16a) structures are considered in the $\mathrm{X}$ direction.

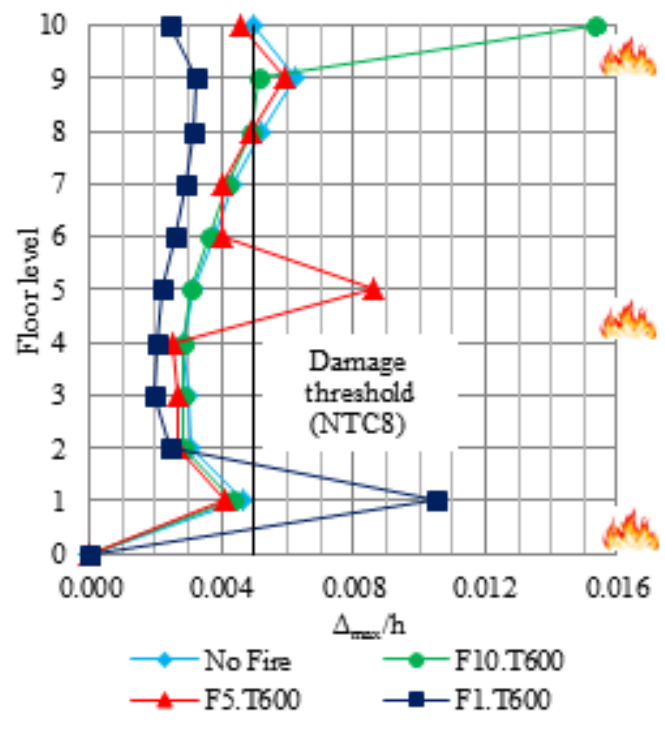

(a) Seismic loads along $\mathrm{X}$ direction.

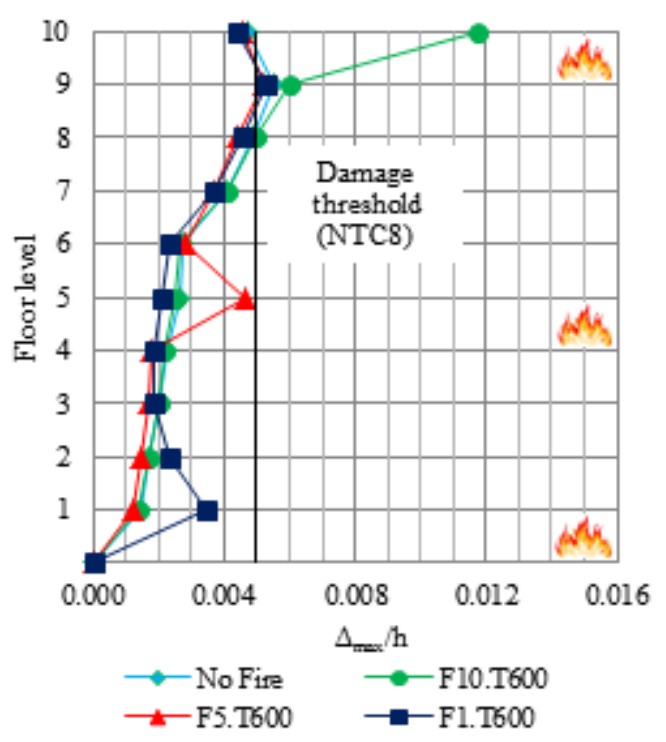

(b) Seismic loads along Y direction.

Figure 15: Maximum storey drift for three fire scenarios: $T=600^{\circ} \mathrm{C}$.

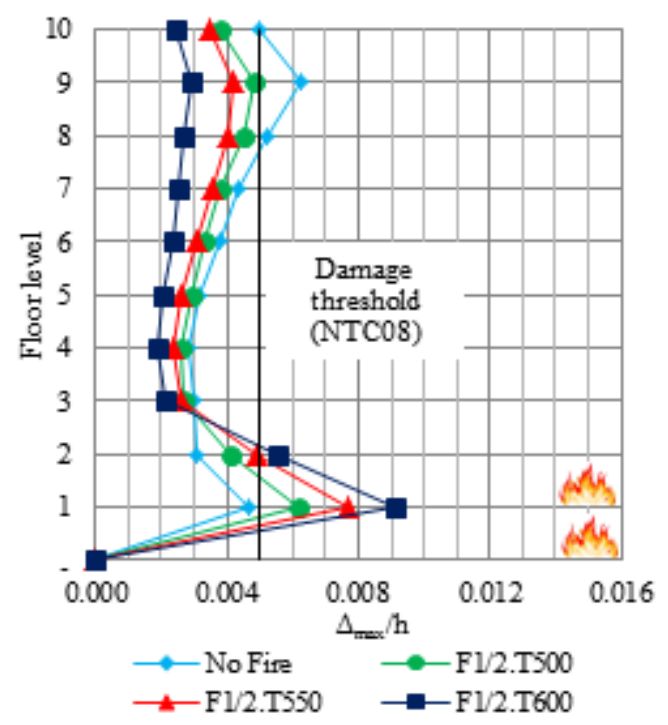

(a) Seismic loads along $\mathrm{X}$ direction.

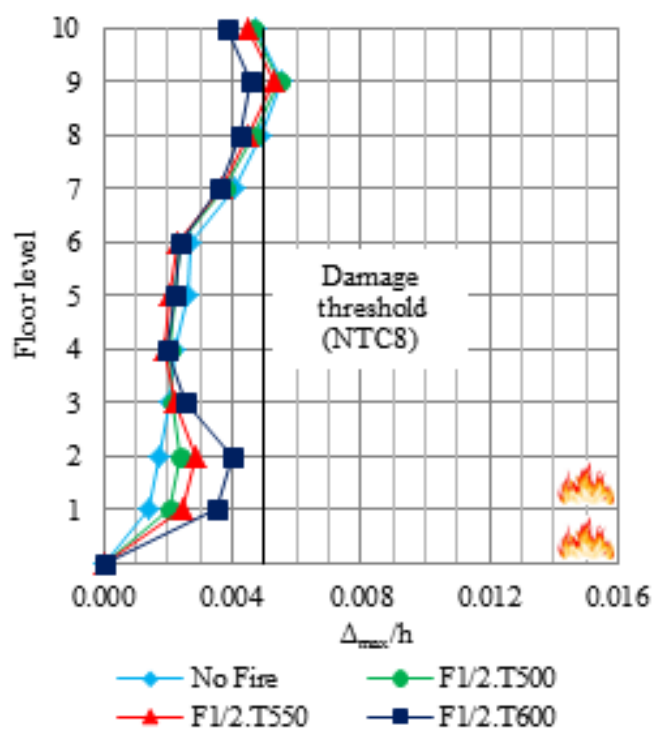

(b) Seismic loads along Y direction.

Figure 16: Maximum storey drift for three fire temperatures: fire scenarios F1/2. 


\section{CONCLUSIONS}

The dynamic response of a ten-storey steel office building in a no fire situation is compared, along the in-plan principal directions, with that in the event of fire, at $500^{\circ} \mathrm{C}$ (i.e. T500), $550^{\circ} \mathrm{C}$ (i.e. T550) and $600^{\circ} \mathrm{C}$ (i.e. T600) temperatures. Four scenarios have been considered assuming the fire compartment confined to the area of the first floor (i.e. F1), the first two (i.e. F1/2) and the upper (i.e. Fi, $\mathrm{i}=5,10$ ) floors. At each storey, along-wind loads are considered based on time histories of the wind velocity for two return periods, in accordance with an equivalent spectrum technique. Real accelerograms, whose response spectra match those adopted by Italian seismic code for a medium-risk seismic zone and medium subsoil class, are considered to simulate seismic loads at the damage limit state.

The numerical results for fire before wind and earthquake show a decrease of the flexural stiffness of the frame members of up to $69 \%$ of the value in the no-fire condition. A significant decrease in plastic moments and a marked narrowing of plastic $N-M$ domains are also observed for the girders and columns, respectively. Under wind loads, the maximum horizontal acceleration exceeds the ISO discomfort threshold at the upper floors, reaching the annoyance range; moreover, the deformability limits imposed by Eurocode 3 on the maximum top displacement and storey drift are not respected. Under seismic loads, the maximum storey drift exceeds the damage threshold imposed by NTC08 at the levels where the fire occurs, while it declines, in comparison with the no-fire condition, on the other levels where the event of fire is not considered.

\section{ACKNOWLEDGEMENTS}

The present work was partially financed by Re.L.U.I.S. (Italian network of university laboratories of earthquake engineering), according to "Convenzione D.P.C.-Re.L.U.I.S. 2014-2016, WPI, Isolation and Dissipation".

\section{REFERENCES}

[1] W.-Y. Wang, B. Liu, V. Kodur, Effect of temperature on strength and elastic modulus of high-strength steel. Journal of Materials in Civil Engineering, 25(2), 174-182, 2013.

[2] C. Scawthorn, J.M. Eidinger, A. Schiff, Fire following earthquake. New York, NY American Society of Civil Engineers, 2005.

[3] G. Della Corte, R. Landolfo, F.M. Mazzolani, Post-earthquake fire resistance of moment resisting steel frames. Fire Safety Journal, 38, 593-612, 2003.

[4] R. Zaharia, D. Pintea, Fire after earthquake analysis of steel moment resisting frames. International Journal of Steel Structures, 9(4), 275-284, 2009.

[5] B. Behnam, H.R. Ronagh, Post-earthquake fire performance-based behavior of unprotected moment resisting 2d steel frames. KSCE Journal of Civil Engineering, 19(1), 274-284, 2015.

[6] E. Nigro, A. Ferraro, G. Cefarelli, The influence of fire scenarios on the structural behaviour of composite steel-concrete buildings. Applied Mechanics and Materials, 82, 368-373, 2011.

[7] Eurocode 3. Design of steel structures - Part 1-1: General rules and rules for buildings. Part 1-2: General rules, structural fire design. C.E.N, European Committee for Standardization, December 2005.

[8] Italian Ministry of Public Works (DM96). Norme tecniche per le costruzioni in zone si- 
smiche e relative istruzioni, D.M. 16-01-1996 and C.M. 10-04-1997, n. 65/AA.GG..

[9] Eurocode 1. Actions on structures - Part 1-2: General actions, actions on structures exposed to fire. C.E.N., European Committee for Standardization, October 2004.

[10] G. Solari, Equivalent wind spectrum technique: theory and applications. Journal of Structural Engineering, 114: 1303-1323, 1998.

[11] Italian Ministry of Infrastructures (NTC08). Nuove norme tecniche per le costruzioni e relative istruzioni, D.M.14-01-2008 e Circolare 02-02-2009, n. 617/C.S.LL.PP..

[12] F. Mazza, A. Vulcano, Control of the along-wind response of steel framed buildings by using viscoelastic or friction dampers. Wind and Structures, 10(3), 233-247, 2007.

[13] F. Mazza, A. Vulcano, Control of the earthquake and wind dynamic response of steelframed buildings by using additional braces and/or viscoelastic dampers. Earthquake Engineering and Strucural Dynamics, 40(2), 155-174, 2011.

[14] F. Mazza, M. Mazza, Nonlinear analysis of spatial framed structures by a lumped plasticity model based on the Haar-Kàrmàn principle. Computational Mechanics, 45, 647664, 2010.

[15] F. Mazza, A distributed plasticity model to simulate the biaxial behaviour in the nonlinear analysis of spatial framed. Computers and Structures, 135, 141-154, 2014.

[16] ISO 834 International Standard, Fire resistance tests, ISO 834-1 Test conditions. Provided by IHS under license with ISO: 31, Genève, Switzerland, 1999.

[17] F. Mazza, F. Alesina, Incremental dynamic analysis of fire-exposed base-isolated r.c. framed buildings subjected to near-fault ground motions. COMPDYN 2015, $5^{\text {th }}$ ECCOMAS Thematic Conference on Computational Methods in Structural Dynamics and Earthquake Engineering, Crete Island, Greece, May 25-27, paper n. 492, 2015.

[18] F. Mazza, A. De Luca, Seismic vulnerability in case of fire of existing r.c. framed buildings: modelling and nonlinear dynamic analysis. COMPDYN 2015, $5^{\text {th }}$ ECCOMAS Thematic Conference on Computational Methods in Structural Dynamics and Earthquake Engineering, Crete Island, Greece, May 25-27, paper n. 491, 2015.

[19] E. Simiu, R. Scanlan, Wind effects on Structures, John Wiley \& Sons, New York, U.S.A., 1996.

[20] ISO/TC 98/SC 3 International Standard Organization, Wind loads on structures, Berlin, Germany, 1990.

[21] F. Mazza, A. Vulcano, Nonlinear dynamic response of r.c. framed structures subjected to near-fault ground motions. Bulletin of Earthquake Engineering, 8, 1331-1350, 2010.

[22] F. Mazza, M. Mazza, Nonlinear modeling and analysis of R.C. framed buildings located in a near-fault area. The Open Construction \& Building Technology Journal, 6, 346-354, 2012.

[23] F. Mazza, Modelling and nonlinear static analysis of reinforced concrete framed buildings irregular in plan. Engineering Structures, 80, 98-108, 2014.

[24] I. Iervolino, G. Maddaloni, E. Cosenza, Eurocode 8 compliant record sets for seismic analysis of structures. Journal of Earthquake Engineering, 12, 54-90, 2008.

[25] F. Mazza, M. Mazza, Nonlinear modeling and analysis of r.c. spatial frames to study the effects of the vertical component of near-fault ground motions. COMPDYN 2015, $3^{\text {rd }}$ ECCOMAS Thematic Conference on Computational Methods in Structural Dynamics and Earthquake Engineering, Corfù, Greece, May 25-28, paper n. 322, 2013. 